Check for updates

Cite this: RSC Adv., 2019, 9, 1933

\title{
An eco-friendly water-assisted polyol method to enhance the aspect ratio of silver nanowires $\uparrow$
}

\author{
Wei Zhao, $\ddagger^{\text {ab }}$ Sha-Sha Wang, (D) $t^{* a}$ Hong-Tao Cao, (D) a Ling-Hai Xie, (D) *a \\ Chao-Shen Hong, ${ }^{a}$ Ling-Zhi Jin, ${ }^{a}$ Meng-Na Yu, ${ }^{a}$ He Zhang, ${ }^{a}$ Zhi-Yun Zhang, ${ }^{b}$ \\ Li-Hua Huang ${ }^{c}$ and Wei Huang (iD ad
}

Received 24th October 2018

Accepted 22nd December 2018

With water as an eco-friendly heterogeneous nucleation accelerator, silver nanowires (Ag NWs) have been successfully prepared with a high aspect ratio ( $>1600)$. The Ag NW-based film exhibits a low sheet resistance of $8.1 \Omega \mathrm{sq}^{-1}$ with a transparency of $81.9 \%$ at $550 \mathrm{~nm}$, showing the potential application of electrode materials in polymer solar cells.

\section{Introduction}

Transparent conductive electrode (TCE) materials have attracted great attention in optoelectronic fields, including touch screens, ${ }^{1}$ organic light emitting diodes (OLEDs) ${ }^{2}$ and organic solar cells (OSCs). ${ }^{3}$ Apart from the costly indium tin oxide (ITO), ${ }^{4}$ there are many different alternatives for TCE, such as carbon nanotubes (CNT) ${ }^{5}$ graphene,${ }^{6}$ metal grids, ${ }^{7}$ and metal nanowires. ${ }^{\mathbf{8} 9}$ Among them, silver nanowires (Ag NWs) are a promising TCE material because of their simple synthesis and the possibility of large-area film fabrication via solution processes such as slot-die coating. ${ }^{10-12}$ With superior mechanical stability as well as transparent conductivity, Ag NW based TCEs could be realized even in a highly stretchable form. ${ }^{\mathbf{1 3 - 1 7}}$ The aspect ratio of Ag NWs is a crucial factor for their application in transparent electrodes, as films of Ag NWs with high aspect ratios tend to have better electrical conductivity and transmittance. However, most metal nanowires synthesized by wet chemistry methods are limited to $10-50 \mu \mathrm{m}$ in length. ${ }^{18} \mathrm{An}$ aspect ratio larger than 800 is required for high performance $\mathrm{Ag}$ NW TCEs with a sheet resistance $<10 \Omega \mathrm{sq}^{-1}$ and a transparency of $\sim 85 \%$ at $550 \mathrm{~nm}$, nearly matching ITO. ${ }^{19-21}$ Recently, Ag NWs

\footnotetext{
${ }^{a}$ Institute of Advanced Materials (IAM), Jiangsu National Synergetic Innovation Center for Advanced Materials (SICAM) Nanjing University of Posts \& Telecommunications (NUPT), 9 Wenyuan Road, Nanjing 210023, China. E-mail: iamsswang@njupt.edu. cn; iamlhxie@njupt.edu.cn

${ }^{b}$ Nanjing College of Information Technology (NCIT), 99 Wenlan Road, Nanjing 210023, China

'Shenzhen Institute of Technology, Shen Zhen, Guangdong, 518000, China

${ }^{d}$ Shaanxi Institute of Flexible Electronics (SIFE), Northwestern Polytechnical University (NPU), 127 West Youyi Road, Xi'an 710072, Shaanxi, China

$\dagger$ Electronic supplementary information (ESI) available: Process of slot-die coating inverted OSCs with $\mathrm{Ag}$ NWs electrode; morphology the core-shell structure of Ag NWs made by PVP of high molecular weight; the performance of TCFs made from different $\mathrm{Ag}$ NWs; the aspect ratio of $\mathrm{Ag}$ NWs made by different polyol method. See DOI: 10.1039/c8ra08810a

$\ddagger$ These authors contributed equally to this work.
}

with multiple scales were used in TCE for highly efficient and flexible OLEDs, and demonstrated a new methodology to enhance the effective electrical area of the Ag NW network transparent conductor. ${ }^{22} \mathrm{Ag}$ NWs with controllable aspect ratios are also meaningful for application in other nontransparent devices such as PM 2.5 filters, ${ }^{23}$ touch panels, ${ }^{24}$ stretchable supercapacitors, ${ }^{17}$ nanogenerators, ${ }^{25}$ fuel cells, ${ }^{26}$ etc. Polyol synthesis is by far the most popular and versatile method for the preparation of Ag NWs. ${ }^{27-29}$ Various polyhydric reducing agents were used in polyol methods, such as ethylene glycol, propylene glycol, glycerol, etc. ${ }^{30,31}$ Recently, glucose was also used as a reducing agent in the hydrothermal synthesis of Ag NWs (200$500 \mu \mathrm{m}$ ) in 22 hours. ${ }^{32}$ However, the typical polyol synthesis of $\mathrm{Ag}$ NWs involves these three procedures: (i) dissolving polymeric capping agents such as poly(vinyl pyrrolidone) (PVP) into ethylene glycol (EG) at an elevated temperature; (ii) introducing a nucleating agent such as $\mathrm{AgCl}$ in the solution and (iii) injecting the precursor (e.g. $\mathrm{AgNO}_{3}$ ) into solution slowly. ${ }^{33-35}$

Besides conventionally optimizing the ratio of chemicals (especially PVP : $\mathrm{AgNO}_{3}$ ), ${ }^{36}$ reaction temperatures, ${ }^{37}$ reaction times, ${ }^{38}$ agitation states, ${ }^{39}$ injection speeds of chemicals, ${ }^{40}$ quite a lot of efforts have also been made to enhance the aspect ratio of Ag NWs. For example, applying a high pressure, ${ }^{41}$ adding varied metal cations ${ }^{42}$ or halide anions ${ }^{20}$ and utilizing successive multistep growth method ${ }^{\mathbf{4 3}}$ were adopted to synthesize Ag NWs with dramatically increased aspect ratio. Most of these strategies are less environmentally friendly with high energy consumption and complicated process. ${ }^{44}$ It is still lack of a facile eco-friendly method to enhance the aspect ratio of Ag NWs.

Herein, we report an eco-friendly water-assisted polyol method to synthesize Ag NWs with a high aspect ratio of $\sim 1600$. In most case of polyol method, water would be removed totally under a temperature of $170{ }^{\circ} \mathrm{C}$ in the first step of $\mathrm{Ag}$ NWs synthesis. ${ }^{\mathbf{1 8 , 4 5}}$ There is little literature focused on the positive effect of water in polyol method. As a polar solvent, proper water content should be critical to the formation of $\mathrm{Ag}$ NWs 
considering the acceleration for nucleation and Ostwald ripening with water, ${ }^{\mathbf{4 6}}$ but the specific influence of water on the reaction of silver source, PVP and EG is still unclear yet. ${ }^{47}$ Some other polar solvent such as ethanol and $\mathrm{N}, \mathrm{N}$-dimethylformamide (DMF) were also used to investigate the formation of $\mathrm{Ag}$ NWs in the previous report, but the length and yield of the products were low. ${ }^{48}$ More importantly, in view of the environmental friendliness of the solvent, we prefer non-toxic PVP aqueous solution rather than else. As far as we know, it is the first time that high aspect ratio (>1500) Ag NWs were synthesized by water-assisted polyol method without other additives, suggesting a unique eco-friendly preparation technology for high aspect ratio metal nanowires.

\section{Experimental section}

\subsection{Synthesis of Ag NWs}

In a typical water-assisted synthesis process, $0.167 \mathrm{~g}$ polyvinyl pyrrolidone (PVP, $M_{\mathrm{w}}=1300$ 000) was added in $10 \mathrm{~mL}$ ethylene glycol (EG), then the solution was stirred and thermally stabilized at $170{ }^{\circ} \mathrm{C}$ for about 30 minutes for a thorough dissolution. To achieve long and thin $\mathrm{Ag}$ NWs, $0.0125 \mathrm{~g}$ silver chloride $(\mathrm{AgCl})$ with $200 \mu \mathrm{L} \mathrm{H}_{2} \mathrm{O}$ was added into the mixture. After 5 minutes, $4 \mathrm{~mL}$ EG solution containing $0.0550 \mathrm{~g} \mathrm{AgNO}_{3}$ was injected into the solution in 10 minutes, and the reaction was left for another 30 minutes to allow the nanowires to grow. Afterwards, acetone and ethanol were used to wash the precipitate with centrifugation at 1000-1500 rpm for $10 \mathrm{~min}$. Finally, the Ag NWs were dispersed in ethanol for use.

\subsection{Fabrication of OSCs with Ag NWs top electrode}

Semi-transparent organic solar cell devices were fabricated on flexible ITO-sputtered PET substrates with the layer sequence PET/ITO/polyethylenimine

(PEI)/poly(3-hexylthiophene) (Р3HT) : phenyl-C61-butyric acid methyl ester (PCBM)/ poly(3,4-ethylene dioxythiophene):polystyrene sulfonate (PEDOT:PSS)/Ag NWs.

The devices were processed using a mini-roll coater (FOM technologies, Denmark). All layers on flexible modules were processed via slot-die coating with a $13 \mathrm{~cm}$ wide slot-die coating head mounted on the mini-roll coater. Coating was performed on a heatable backing roll just like previous report. ${ }^{49}$ The details of device fabrication were shown in Fig. S1.†

\subsection{Characterization}

$\mathrm{Ag}$ NWs and their derived films were characterized by scanning electron microscopy (SEM, Hitachi S-4800), UV-visible spectrophotometer (UV-Vis, Shimadzu, UV-3600), X-ray diffractometer (XRD, Bruker) and the sheet resistance (SR) was evaluated by four-point probe (RTS-8, 4 probes tech) measurement at room temperature. The current density-voltage $(J-V)$ characteristics were examined using a Keithley 2400 source measuring unit under simulated AM 1.5 illumination $\left(100 \mathrm{~mW} \mathrm{~cm}^{-2}\right)$ with a solar simulator.

\section{Results and discussion}

To avoid the effect of other cations in the polyol reaction, $\mathrm{AgCl}$ was chosen to be the nucleating agent. The SEM analysis of the product revealed the formation of long, thin Ag NWs in a high yield. Fig. 1a and b shows the SEM images of Ag NWs synthesized with trace water ( 2 vol\%) (PVP molecular weight is 1300 000). The average length and diameter were calculated by the statistical distribution of about $100 \mathrm{Ag}$ NWs from the SEM images. The Ag NWs exhibit a uniform morphology with an average diameter of $\sim 45 \mathrm{~nm}$ and length of $\sim 73 \mu \mathrm{m}$, showing a high aspect ratio over 1600. By comparison, Ag NWs synthesised by the same progress without water only show an average diameter of $\sim 70 \mathrm{~nm}$ and length of $\sim 20 \mu \mathrm{m}$, as disclosed in Fig. $1 \mathrm{c}$ and $\mathrm{d}$, similar to the previous reports. ${ }^{33,34}$ It's worth mentioning that the waterless-synthesized product contains much more nanoparticles and nanorods than the water-assisted product, indicating the crystallization promoting effect of water.

Optical absorption characterization could also provide key clues to the morphology evolution of the products. Fig. 2a shows the normalized UV-Vis spectra recorded from alcohol suspensions of the Ag NWs produced with or without water. The waterassisted Ag NWs exhibit a sharp peak at $374 \mathrm{~nm}$ with a slight
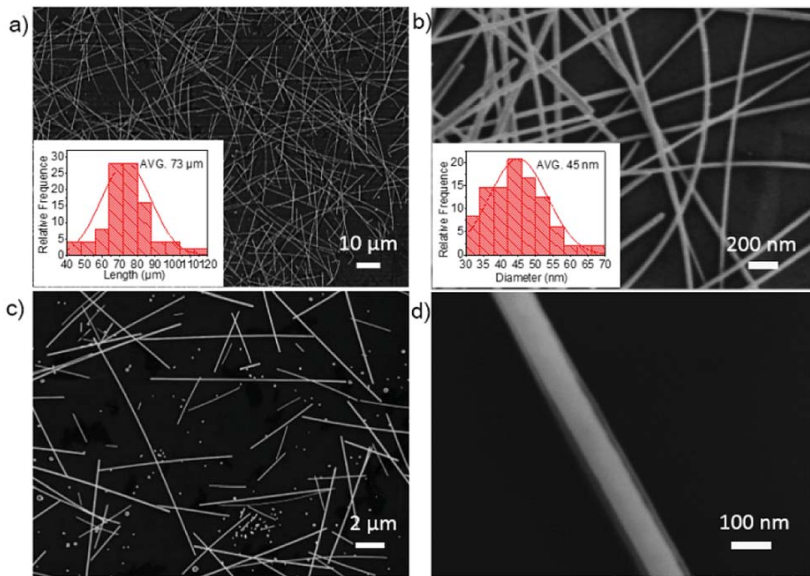

Fig. 1 ( $a$ and b) SEM images of Ag NWs made by 2 vol\% water-assisted polyol method. The inset histogram showed the statistical distribution of length and diameter. (c and d) SEM images of Ag NWs using the same recipe without water.
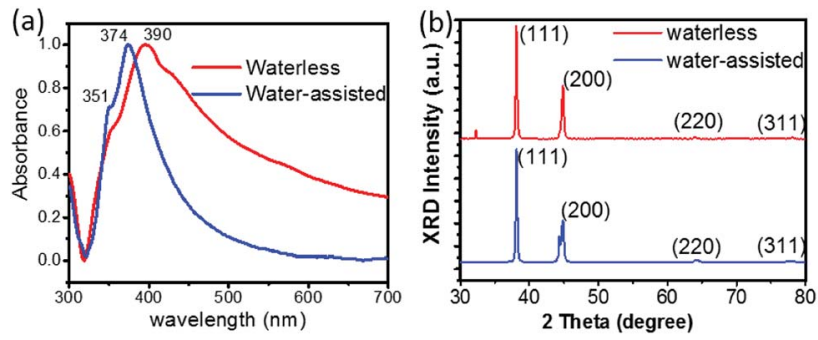

Fig. 2 (a) UV-Vis and (b) XRD patterns of the Ag NWs obtained by different polyol process. 
shoulder while the waterless Ag NWs exhibit a peak at $390 \mathrm{~nm}$. The spectrum blue shift and the narrow bandwidth demonstrate the diameter decrease for water-assisted Ag NWs. ${ }^{18,35}$ Furthermore, the water-assisted Ag NWs show a more distinct peak at $\sim 351 \mathrm{~nm}$, which belongs to the longitudinal plasmon. ${ }^{23}$ However, the waterless Ag NWs also display a broad peak around $436 \mathrm{~nm}$, which could be attributed to the surface plasmon resonance (SPR) band of silver nanoparticles. ${ }^{46,50}$

In addition, the structure of Ag NWs was studied by X-ray diffraction (XRD) as shown in Fig. 2b. The nanowires exhibit four typical peaks, which correspond to the diffractions of (111), (200), (220), (311) Ag planes, consistent with the face-centered cubic (fcc) crystalline phase. ${ }^{50}$ The minor peak around $32^{\circ}$ in the XRD pattern of waterless $\mathrm{Ag}$ NWs indicates the presence of $\mathrm{Ag} \mathrm{Cl}$ nanoparticles. ${ }^{36}$ The slight split of peak around $44^{\circ}$ in the XRD pattern of water-assisted Ag NWs is due to the presence of a strained face-centered tetragonal (fct) phase, which was usually formed during the growth of long Ag NWs (up to $\sim 100$ $\mu \mathrm{m}$ in length). ${ }^{51}$ It is worth noting that the ratio of intensity between (111) and (200) peaks exhibits a relatively higher value for water-assisted Ag NWs than waterless Ag NWs, indicating the enrichment of (111) crystalline planes in the silver nanowires, which is due to the morphological evolution from Ag nanoparticles to nanowires. ${ }^{36,50}$

In order to give a detailed water-assisted Ag NWs evolution, we tested the impact on Ag NWs morphology by changing the water content and adding sequence. Compared to the typical products in Fig. 1a, Ag NWs synthesized with half water content ( $1 \mathrm{vol} \%$ water-assisted) were shorter wires with some particles (Fig. 3a), while the sample synthesized with double water content (4 vol\% water-assisted) exhibits a lot of short nanorods and particles (Fig. $3 \mathrm{~b}$ ), indicating the aspect ratio of waterassisted Ag NWs and the uniformity are strongly affected by the water content. Furthermore, the adding occasion of water was also investigated. As the Ag NWs formation process could be considered as two steps: the first step is the nucleation stage with $\mathrm{AgCl}$ as the nucleating agent and the second step is the growth stage with $\mathrm{AgNO}_{3}$ as the reactive material. Instead of adding water in the nucleation stage, when we added 2 vol\% water along with $\mathrm{AgNO}_{3}$, the products exhibit low aspect ratio rods with many particles, as shown in Fig. 3c. The result confirms that the water effect is mainly in the nucleation stage.

There are few reports about the using of trace water in $\mathrm{Ag}$ NWs synthesis. Jia concluded that $\mathrm{Ag}$ from $\mathrm{AgCl}$ did contribute somewhat in the heterogeneous nucleation and multiplied twinned particles(MTPs) formation stage, this can be accelerated by adding water at $160{ }^{\circ} \mathrm{C} .{ }^{46}$ Yang et al. supposed that as a typical ionic compound and an excellent thermal conductor, water (together with oxygen) plays a subtle role in effectively improving the charge transfer process involved in the growth of Ag NWs; and promoting the homogenization during the reaction process, which is especially useful for the large scale production of high quality Ag NWs. ${ }^{47}$

It's reported that the yields and aspect ratios of silver nanowires were increased with increasing the molecular weight of PVP. ${ }^{52}$ To study the water effect with different PVP, Ag NWs were prepared with lower molecular weight PVP (58 000) as shown in Fig. $\mathrm{S} 2, \uparrow$ indicating that the water effect is not so obvious in the use of PVP 58000. Furthermore, no core-shell structure was observed in the Ag NWs fabricated with PVP 58 000, while excess PVP 1300000 was often prone to cover on the nanoparticles and present core-shell structures, as shown in Fig. S3..$^{53}$

The possible reasons for the positive role of water with PVP were discussed as follows. It's because that higher molecular weight PVP leads to more viscous solution, which is hindering for reducing the free energy of Ag (100) via surface adsorption. ${ }^{54}$ There is a strong interaction between water and PVP, which may hinder the interactions between the reacting species and the excess PVP 1300 000, inducing the enhanced Ag NWs aspect ratio. The problem of low solubility usually exists on the reduction of metal cations in non-aqueous solvents, especially with long chain-length polymers. ${ }^{46,47}$ Due to the long chain length, the EG solution containing PVP with a high molecular weight of 1300000 would possess a high viscosity. According to the Stokes-Einstein equation, a high viscosity $(\eta)$ solvent will result in a small diffusion coefficient $(D)$ for a spherical particle with a radius $(r)$, as indicated by the following equation:

$$
D=k_{\mathrm{B}} T / 6 \pi \eta
$$

In which $k_{\mathrm{B}}$ is the Boltzmann constant and $T$ is the absolute temperature. As a result, the probability for the Ag clusters to collide with each other will be reduced with PVP of high molecular, leading to shorter nanowires and nanorods. On the other hand, PVP with a higher molecular weight contributes to more uniform Ag NWs in higher purity. ${ }^{18}$ Fortunately, nucleation and growth of metal nanoclusters in solution are more greatly influenced by the polarity of the solvent than the viscosity. ${ }^{55}$ The transfer of electrons between the reacting species tends to be easier in polar solvents than the nonpolar ones. ${ }^{47}$ The presence of a proper amount of water probably promotes the proton hopping on the surface of the materials, which can facilitate the charge transfer process. ${ }^{56}$ The improved

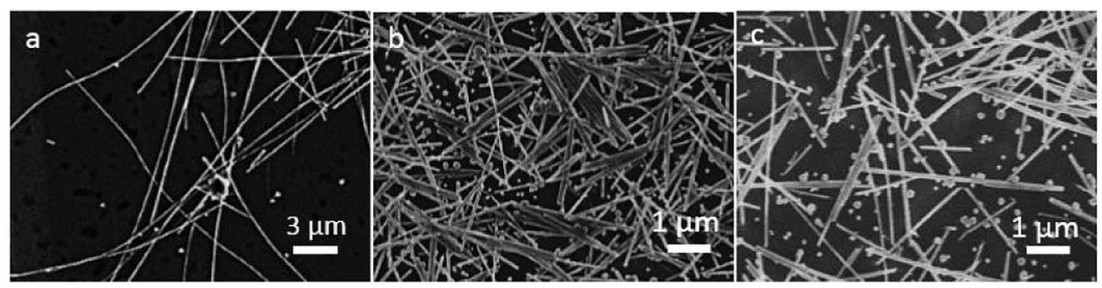

Fig. $3 \mathrm{SEM}$ images of the products by (a) 1 vol\%, (b) 4 vol\% water added with $\mathrm{AgCl}$ and (c) 2 vol\% water added with $\mathrm{AgNO}_{3}$. 
polarity accelerates the reaction speed and enhances the Ostwald ripening process, which result in effective production of long aspect ratio Ag NWs with fewer nanoparticles. The accelerator effect of water could be proved by the SEM images (Fig $\mathrm{S} 4 \dagger$ ) of polyol reaction for 5 minutes. With the addition of water, the quantity of large particles decreased dramatically and numerous small nanoparticles (NPs) appeared. The reason is that the heterogeneous nucleation rates of Ag NWs were accelerated with water introduced. ${ }^{46}$

However, if there was too much water remained during the $\mathrm{AgNO}_{3}$ adding stage, it would continually evaporate and bubble along with the $\mathrm{Ag}^{+}$reduction, causing fluctuations in the growth of MTPs, leading to more short nanorods and NPs. As mentioned above, 2 vol\% water was enough to accelerate the nucleation and Ostwald ripening of Ag species, enhancing the aspect ratio and yield of Ag NWs. Much more water would have a negative impact. Excess water may degrade $\mathrm{Ag}$ NWs aspect ratio during the $\mathrm{Ag}$ NWs growth stage before it is vaporized to air. Therefore, we draw a conclusion that a moderate amount of water should be added in the step of $\mathrm{AgCl}$ addition in a typical trace water-assisted polyol process.

Transparent electrode is one of the critical components for transparent optoelectronic devices, especially in semitransparent solar cells for building integrated photovoltaic applications. ${ }^{57,58}$ Solution-processed Ag NWs networks show excellent transparency, electrical conductivity, and mechanical flexibility, which have been extensively investigated as flexible and low-cost electrodes to replace traditional ITO electrode. To exam the opto-electronic performances of our Ag NWs TCE, inverted semi-transparent organic solar cells with slot-die coated Ag NWs networks as the top electrode was tested. With respect to $\mathrm{Ag}$ NWs electrode for OSCs, most of Ag NWs networks were used as bottom electrode and organic layers were deposited on top of it. ${ }^{12,59}$ Only a few papers reported Ag NWs as top electrode in OSCs. ${ }^{49,57}$ For organic solar cells, solutionprocessed poly(3,4-ethylene dioxythiophene): poly(styrene sulfonate) (PEDOT:PSS) is the most well-known anode buffer layer owing to its suitable work function (WF), good charge transport ability, and excellent visible light transparency. ${ }^{60}$ However, physical and chemical interactions between the conductive ink and the organic layer may affect the wettability, which would lead to poor quality of film formation during coating.

The layer structure of our OSCs with different Ag NWs top electrodes was shown in Fig. 4 a and the $J-V$ curves was shown in Fig. 4b. While the open-circuit voltage $\left(V_{\mathrm{OC}}\right)$ remained unchanged, both short-circuit current density $\left(J_{\mathrm{sC}}\right)$ and fill factor(FF) increased significantly by the changing of top Ag NWs electrode, then the power conversion efficiencies (PCE) increased from $0.98 \%$ to $1.30 \%$ (see Table 1 ), which is comparable to the previous report. ${ }^{61}$ This could be partially attributed to the decrease of sheet resistance of water-assisted Ag NWs film $\left(R_{\mathrm{s}}=8.1 \Omega \mathrm{sq}^{-1}, T \%=81.9\right.$ and haze $\left.=4.68 \%\right)$ relative to waterless Ag NWs $\left(R_{\mathrm{S}}=19.9 \Omega \mathrm{sq}^{-1}, T \%=80.9\right.$ and haze $=$ $8.50 \%$ ), as shown in Table S1. $\dagger$ Haze is another important parameter for TCE in addition to transparency and sheet resistance. Low-haze TCE made by Ag NWs with a high aspect (a)
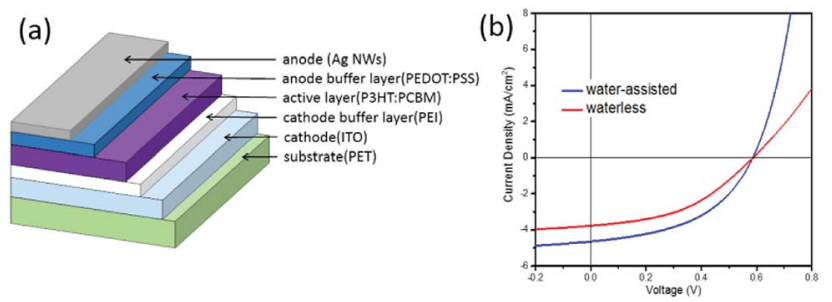

Fig. 4 (a) The schematic structure of the inverted OSCs with printed Ag NWs electrodes, (b) the comparison of $J-V$ curves between devices with different Ag NWs top electrode.

Table 1 Performances of the OSCs with different top electrodes

\begin{tabular}{lclll}
\hline Top electrode $(\mathrm{Ag} N W s)$ & $V_{\mathrm{OC}}(\mathrm{V})$ & $J_{\mathrm{SC}}\left(\mathrm{mA} \mathrm{cm}^{2}\right)$ & $\mathrm{FF}(\%)$ & PCE $(\%)$ \\
\hline Water-assisted & 0.58 & 4.66 & 48 & 1.30 \\
Waterless & 0.58 & 3.77 & 45 & 0.98 \\
\hline
\end{tabular}

ratio ( 900) was always used in OLED,${ }^{24}$ while high haze TCE was always used in OSC. ${ }^{62}$ The lower haze of water-assisted Ag NWs may due to fewer nanoparticles in the Ag NWs sample. It's also reported that electrochemical etching could precisely tailor the diameter of nanowires with high transmittance and high haze, which is a promising approach to increase haze of Ag NWs based TCE in OSCs. ${ }^{62}$

\section{Conclusions}

In summary, we have demonstrated a facile and eco-friendly water-assisted polyol synthetic route for Ag NWs. Trace water not only facilitated the nucleation of Ag nanoclusters but also blocked the interactions between the reacting species and the surplus of polymer chain of PVP with high molecular weight, resulting in a high aspect ratio over 1600 of Ag NWs. Based on the Ag NWs, the flexible TCE was fabricated using a slot-die coat process and served as the top electrode in semitransparent OSCs. With the excellent opto-electrical film properties $\left(8.1 \Omega \mathrm{sq}^{-1}\right.$, with $81.9 \%$ transmittance at $\left.550 \mathrm{~nm}\right)$, water-assisted Ag NWs TCE performed better in OSCs device, suggesting an unique eco-friendly preparation technology for high aspect ratio metal nanowires.

\section{Conflicts of interest}

There are no conflicts of interest.

\section{Acknowledgements}

This work was supported by the National Natural Science Foundation of China $(61604081,61605090$, U1301243), the Natural Science Foundation of the Jiangsu Higher Education Institutions (16KJB430023, 16KJB430034), Doctoral Fund of Ministry of Education of China (20133223110007), Excellent science and technology innovation team of Jiangsu Higher Education Institutions (2013), Natural Science Foundation of 
Jiangsu Province, China (BM2012010), the Six Talent Peaks Project of Jiangsu Province (XCL-CXTD-009), Project funded by the Priority Academic Program Development of Jiangsu Higher Education Institutions, PAPD (YX03002), NUPTSF (NY215055, NY215061). The authors are also thankful for the support of the Scientific Research Fund Project of Nanjing College of Information Technology (YK20160301, YB20170301) and Jiangsu Students' Innovation \& Entrepreneurship Training Program (201713112021X, 201713112009Y)

\section{Notes and references}

1 S. Cho, S. Kang, A. Pandya, R. Shanker, Z. Khan, Y. Lee, J. Park, S. L. Craig and H. Ko, ACS Nano, 2017, 11, 4346-4357.

2 H. Zheng, Y. Zheng, N. Liu, N. Ai, Q. Wang, S. Wu, J. Zhou, D. Hu, S. Yu, S. Han, W. Xu, C. Luo, Y. Meng, Z. Jiang, Y. Chen, D. Li, F. Huang, J. Wang, J. Peng and Y. Cao, Nat. Commun., 2013, 4, 1971.

3 K. P. Loh, S. W. Tong and J. Wu, J. Am. Chem. Soc., 2016, 138, 1095-1102.

4 R. Bel Hadj Tahar, T. Ban, Y. Ohya and Y. Takahashi, J. Appl. Phys., 1998, 83, 2631-2645.

5 Z. D. Liu, Z. Y. Yin, Z. H. Du, Y. Yang, M. M. Zhu, L. H. Xie and W. Huang, Nanoscale, 2014, 6, 5110-5115.

6 S. Jia, H. D. Sun, J. H. Du, Z. K. Zhang, D. D. Zhang, L. P. Ma, J. S. Chen, D. G. Ma, H. M. Cheng and W. C. Ren, Nanoscale, 2016, 8, 10714-10723.

7 L. Hu, H. Wu and Y. Cui, MRS Bull., 2011, 36, 760-765.

8 Y. Liu, J. Zhang, H. Gao, Y. Wang, Q. Liu, S. Huang, C. F. Guo and Z. Ren, Nano Lett., 2017, 17, 1090-1096.

9 M. Wan, J. Tao, D. Jia, X. Chu, S. Li, S. Ji and C. Ye, CrystEngComm, 2018, 20, 2834-2840.

10 Y. Xia, Y. Xiong, B. Lim and S. E. Skrabalak, Angew. Chem., Int. Ed., 2009, 48, 60-103.

11 N. Espinosa, R. R. Sondergaard, M. Jorgensen and F. C. Krebs, ChemSusChem, 2016, 9, 893-899.

12 D. Angmo, T. R. Andersen, J. J. Bentzen, M. Helgesen, R. R. Søndergaard, M. Jørgensen, J. E. Carlé, E. Bundgaard and F. C. Krebs, Adv. Funct. Mater., 2015, 25, 4539-4547.

13 J. H. Cho, D. J. Kang, N. S. Jang, K. H. Kim, P. Won, S. H. Ko and J. M. Kim, ACS Appl. Mater. Interfaces, 2017, 9, 4090540913.

14 S. Hong, H. Lee, J. Lee, J. Kwon, S. Han, Y. D. Suh, H. Cho, J. Shin, J. Yeo and S. H. Ko, Adv. Mater., 2015, 27, 4744-4751.

15 J. Jung, H. Lee, I. Ha, H. Cho, K. K. Kim, J. Kwon, P. Won, S. Hong and S. H. Ko, ACS Appl. Mater. Interfaces, 2017, 9, 44609-44616.

16 P. Lee, J. Ham, J. H. Lee, S. Hong, S. Han, Y. D. Suh, S. E. Lee, J. Yeo, S. S. Lee, D. Lee and S. H. Ko, Adv. Funct. Mater., 2014, 24, 5671-5678.

17 H. Lee, S. Hong, J. Lee, Y. D. Suh, J. Kwon, H. Moon, H. Kim, J. Yeo and S. H. Ko, ACS Appl. Mater. Interfaces, 2016, 8, 15449-15458.

18 R. R. da Silva, M. Yang, S. I. Choi, M. Chi, M. Luo, C. Zhang, Z. Y. Li, P. H. Camargo, S. J. Ribeiro and Y. Xia, ACS Nano, 2016, 10, 7892-7900.
19 R. M. Mutiso, M. C. Sherrott, A. R. Rathmell, B. J. Wiley and K. I. Winey, ACS Nano, 2013, 7, 7654-7663.

20 B. Li, S. Ye, I. E. Stewart, S. Alvarez and B. J. Wiley, Nano Lett., 2015, 15, 6722-6726.

21 S. M. Bergin, Y. H. Chen, A. R. Rathmell, P. Charbonneau, Z. Y. Li and B. J. Wiley, Nanoscale, 2012, 4, 1996-2004.

22 J. Lee, K. An, P. Won, Y. Ka, H. Hwang, H. Moon, Y. Kwon, S. Hong, C. Kim, C. Lee and S. H. Ko, Nanoscale, 2017, 9, 1978-1985.

23 S. Jeong, H. Cho, S. Han, P. Won, H. Lee, S. Hong, J. Yeo, J. Kwon and S. H. Ko, Nano Lett., 2017, 17, 4339.

24 H. Moon, P. Won, J. Lee and S. H. Ko, Nanotechnology, 2016, 27, 295201.

25 C. Liu, B. Hua, S. You, C. Bu, X. Yu, Z. Yu, N. Cheng, B. Cai, H. Liu, S. Li, L. Zhang, S. Wang, K. Liu, N. Zhang, W. Liu, S. Guo and X.-Z. Zhao, Appl. Phys. Lett., 2015, 106, 163901.

26 X. Yan, A. Xu, L. Zeng, P. Gao and T. Zhao, Energy Technol., 2018, 6, 140-143.

27 Y. Sun and Y. Xia, Adv. Mater., 2002, 14, 833-837.

28 D. R. Whitcomb, A. R. Clapp, P. Bühlmann, J. C. Blinn and J. Zhang, Cryst. Growth Des., 2016, 16, 1861-1868.

29 H. Sim, S. Bok, B. Kim, M. Kim, G. H. Lim, S. M. Cho and B. Lim, Angew. Chem., Int. Ed., 2016, 55, 11814-11818.

30 H. Sim, C. Kim, S. Bok, M. K. Kim, H. Oh, G. H. Lim, S. M. Cho and B. Lim, Nanoscale, 2018, 10, 12087-12092.

31 Y. Li, S. Guo, H. Yang, Y. Chao, S. Jiang and C. Wang, RSC Adv., 2018, 8, 8057-8063.

32 B. Bari, J. Lee, T. Jang, P. Won, S. H. Ko, K. Alamgir, M. Arshad and L. J. Guo, J. Mater. Chem. A, 2016, 4, 1136511371.

33 L. Hu, H. S. Kim, J.-Y. Lee, P. Peumans and Y. Cui, ACS Nano, 2010, 4, 2955-2963.

34 P. C. Hsu, X. Liu, C. Liu, X. Xie, H. R. Lee, A. J. Welch, T. Zhao and Y. Cui, Nano Lett., 2015, 15, 365-371.

35 Y. Liu, Y. Chen, R. Shi, L. Cao, Z. Wang, T. Sun, J. Lin, J. Liu and W. Huang, RSC Adv., 2017, 7, 4891-4895.

36 C. Wang, B. Cheng, H. Zhang, P. Wan, L. Luo, Y. Kuang and X. Sun, Nano Res., 2016, 9, 1532-1542.

37 Y. Zhang, J. Guo, D. Xu, Y. Sun and F. Yan, ACS Appl. Mater. Interfaces, 2017, 9, 25465-25473.

38 X. Li, L. Wang and G. Yan, Cryst. Res. Technol., 2011, 46, 427438.

39 A. Amirjani, P. Marashi and D. H. Fatmehsari, Int. Nano Lett., 2015, 6, 41-44.

40 A. Amirjani, P. Marashi and D. H. Fatmehsari, Colloids Surf., A, 2014, 444, 33-39.

41 E.-J. Lee, M.-H. Chang, Y.-S. Kim and J.-Y. Kim, APL Mater., 2013, 1, 042118.

42 K. E. Korte, S. E. Skrabalak and Y. Xia, J. Mater. Chem., 2008, 18, 437-441.

43 J. H. Lee, P. Lee, D. Lee, S. S. Lee and S. H. Ko, Cryst. Growth Des., 2012, 12, 5598-5605.

44 T. Cheng, Y.-Z. Zhang, W.-Y. Lai, Y. Chen, W.-J. Zeng and W. Huang, J. Mater. Chem. C, 2014, 2, 10369-10376.

45 S. Zhu, Y. Gao, B. Hu, J. Li, J. Su, Z. Fan and J. Zhou, Nanotechnology, 2013, 24, 335202. 
46 D. Jia, Y. Zhao, W. Wei, C. Chen, G. W. Lei, M. J. Wan, J. Q. Tao, S. X. Li, S. L. Ji and C. H. Ye, CrystEngComm, 2017, 19, 148-153.

47 C. Yang, Y. Tang, Z. Su, Z. Zhang and C. Fang, J. Mater. Sci. Technol., 2015, 31, 16-22.

48 M. Giersig, I. Pastoriza-Santos and L. M. Liz-Marzán, J. Mater. Chem., 2004, 14, 607-610.

49 L. Lucera, F. Machui, H. D. Schmidt, T. Ahmad, P. Kubis, S. Strohm, J. Hepp, A. Vetter, H. J. Egelhaaf and C. J. Brabec, Org. Electron., 2017, 45, 209-214.

50 Y. Sun, Y. Yin, B. T. Mayers, T. Herricks and Y. Xia, Chem. Mater., 2002, 14, 4736-4745.

51 C. L. Kuo and K. C. Hwang, Langmuir, 2012, 28, 3722-3729.

52 J.-J. Zhu, C.-X. Kan, J.-G. Wan, M. Han and G.-H. Wang, J. Nanomater., 2011, 2011, 1-7.

53 X. Zeng, B. Zhou, Y. Gao, C. Wang, S. Li, C. Y. Yeung and W. Wen, Nanotechnology, 2014, 25, 495601.

54 X. Xia, J. Zeng, L. K. Oetjen, Q. Li and Y. Xia, J. Am. Chem. Soc., 2012, 134, 1793-1801.

55 D. V. Goia, J. Mater. Chem., 2004, 14, 451.
56 L. R. Merte, G. Peng, R. Bechstein, F. Rieboldt, C. A. Farberow, L. C. Grabow, W. Kudernatsch, S. Wendt, E. Laegsgaard, M. Mavrikakis and F. Besenbacher, Science, 2012, 336, 889-893.

57 H. Lu, J. Lin, N. Wu, S. Nie, Q. Luo, C.-Q. Ma and Z. Cui, Appl. Phys. Lett., 2015, 106, 093302.

58 R. Betancur, P. Romero-Gomez, A. Martinez-Otero, X. Elias, M. Maymó and J. Martorell, Nat. Photonics, 2013, 7, 9951000.

59 D. Pu, W. Zhou, Y. Li, J. Chen, J. Chen, H. Zhang, B. Mi, L. Wang and Y. Ma, RSC Adv., 2015, 5, 100725-100729.

60 R. Po, C. Carbonera, A. Bernardi and N. Camaioni, Energy Environ. Sci., 2011, 4, 285-310.

61 D. Angmo, H. F. Dam, T. R. Andersen, N. K. Zawacka, M. V. Madsen, J. Stubager, F. Livi, R. Gupta, M. Helgesen, J. E. Carlé, T. T. Larsen-Olsen, G. U. Kulkarni, E. Bundgaard and F. C. Krebs, Energy Technol., 2014, 2, 651-659.

62 Y. Fang, Z. Wu, J. Li, F. Jiang, K. Zhang, Y. Zhang, Y. Zhou, J. Zhou and B. Hu, Adv. Funct. Mater., 2018, 28, 1705409. 